\section{Splitting of the Polyethylene \\ Coverings as a Previously \\ Unrecognized Complication \\ of Oesophageal Metallic Covered \\ Stent (Gianturco-Rösch) Inserted for Malignant Stricture}

Dysphagia is a common, distressing, and often progressive presenting symptom in patients with malignant oesophageal tumours. Oesophageal self-expanding metallic stents have become an increasingly often-used and effective means of providing rapid improvement of dysphagia in patients with unresectable tumours $(1,2)$ However, tumour overgrowth and stent migration can occur, requiring further intervention $(3,4)$. Other problems include reflux oesophagitis, chest pain, pharyngeal discomfort, bleeding, and bolus obstruction. Uncovered stents can become incorporated into the oesophageal wall, but have the disadvantage that tumour ingrowth across the mesh is possible. Stents that are covered (with materials consisting of polyethylene, polyurethane, or silicone) usually prevent tumour ingrowth, but dislocation occurs more frequently. In addition, proximal or distal neoplastic obstruction can occur due to longitudinal progression. We describe here a new complication associated with covered oesophageal stents

A 65-year-old woman presented with a two-month history of progressive dysphagia and weight loss. Gastroscopy showed a 10 -cm tight malignant stricture, which was treated with balloon dilation before insertion of a 14-cm covered stent (GianturcoRösch), with good symptomatic improvement. Five months later, she complained of nausea, vomiting, and a gurgling sensation on drinking fluids, with regurgitation soon after meals. The gastroscopic and barium swallow findings are shown in Figures 1 and 2. She was treated conservatively, as she was able to swallow, although the gurgling sensation persisted.

The modified Gianturco-Rösch stent consists of a wide Z-mesh of stainless steel, covered over its entire length by a polyethylene film with barbs in the centre segment. However, as illustrated in this case, the different layers of the polyethylene films are liable to separate, and can potentially cause laryngeal problems.

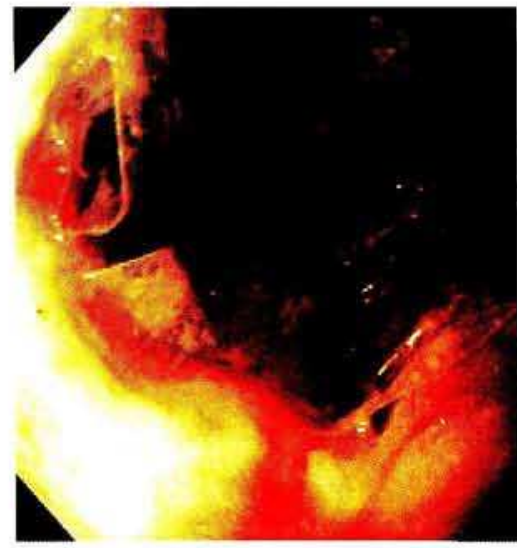

Figure 1: This endoscopic image shows the split ends of the inner and outer layers of the upper parts of the plastic membranes of the metallic stent (five months after insertion), forming pockets in which liquid and food were able to accumulate. This was the cause of the gurgling sensation experienced by the patient, but did not result in actual dysphagia.

\section{V.S. Wong', C. J. Garvey'2, A. I. Morris'}

${ }^{1}$ Dept. of Gastroenterology

${ }^{2}$ Dept. of Radiology, Royal Liverpool

University and Broadgreen Hospital

National Health Service Trust, Prescott

Road, Liverpool, United Kingdom

\section{References}

1. Knyrim K, Wagner HJ, Bethge $\mathrm{N}$, et al. A controlled trial of an expansile metal stent for palliation of oesophageal obstruction due to inoperable cancer. $\mathrm{N}$ Engl J Med 1993; 328: 1302-7.

2. Kozarek RA. Expandable endoprosthesis for gastrointestinal stenoses. Gastrointest Endosc Clin North Am 1994; 4: 279-95.

3. Sturgess R, Morris Al. Metal stents in the oesophagus. Gut 1995; 37: 593-4.

4. Kozarek RA, Ball TJ, Brandabur JJ, et al. Expandable versus conventional oesophageal prostheses: easier insertion may not preclude subsequent stent-related problems. Gastrointest Endosc 1996; 43: 204-8.

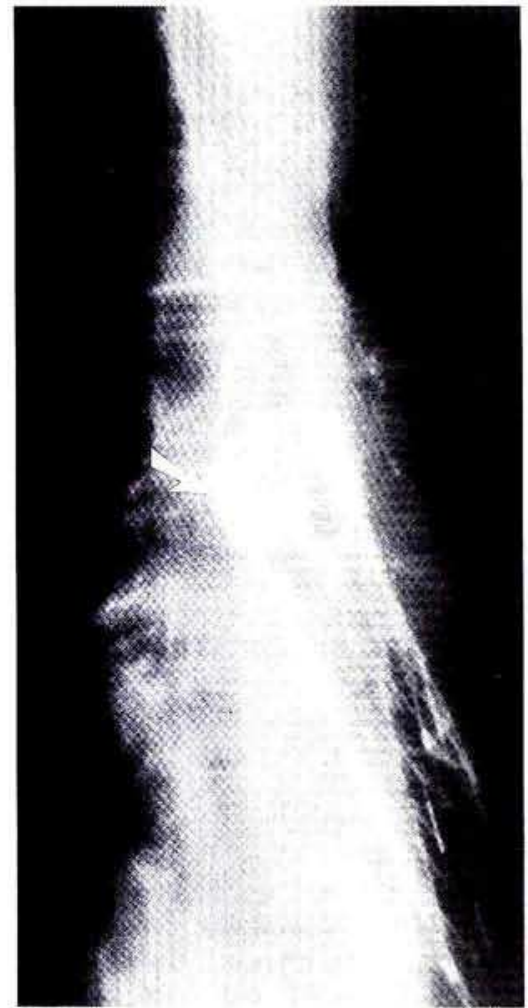

Figure 2: The anteroposterior view in a barium swallow demonstrates barium collection pockets (arrow) lying in the upper parts of the wellpositioned metallic stent across the malignant stricture (moderately differentiated squamouscell carcinoma)

Corresponding Author

V. S. Wong, M.D.

Senior Registrar

Dept. of Gastroenterology

Fazakerlay Hospital,

Aintree Hospital NHS Trust

Longmoor Lane

Liverpool L97AL

United Kingdom

Fax: + 44-151-529-3239 